Ensino, Saúde e Ambiente - V10 (1), pp. 203-217, Abril. 2017

\title{
APROVEITAMENTO INTEGRAL DOS ALIMENTOS: QUALIDADE NUTRICIONAL E CONSCIÊNCIA AMBIENTAL NO AMBIENTE ESCOLAR
}

\section{INTEGRAL UTILIZATION OF FOODS: NUTRITIONAL QUALITY AND ENVIRONMENTAL CONSCIOUSNESS IN SCHOOL ENVIRONMENT}

\author{
Michelle Efigênia Moreno Gomes ${ }^{1}$ \\ Catarina Teixeira ${ }^{2}$ \\ ${ }^{1}$ Especialista em Educação Ambiental pela UFLA. Docente na Escola Estadual Prefeito Jacy Junqueira \\ Gazola, Três Pontas-MG. michelleeepjjg@ yahoo.com.br \\ ${ }^{2}$ Mestre em Educação pela UFLA, Doutoranda em Educação pela UNESP-campus Rio Claro, SP. \\ Docente na Universidade Federal do Triângulo Mineiro-UFTM. catarina.teixeira@uftm.edu.br
}

\section{RESUMO}

A pesquisa destaca a importância da utilização integral dos alimentos para manutenção de uma boa saúde, minimização do desperdício e a diminuição da produção de lixo orgânico. Tendo como objetivo sensibilizar os alunos de uma escola pública estadual no município de Três Pontas - MG sobre o aproveitamento integral dos alimentos. $\mathrm{O}$ trabalho iniciou com a aplicação de um questionário que utilizado como base para realização de uma palestra, no qual foram discutidos os benefícios da utilização integral dos alimentos. Em seguida foi preparada uma receita com a participação dos alunos e depois construído com os mesmos um caderno com receitas que utilizam integralmente os alimentos. Ao final do projeto percebemos que a ideia sensibilizou grande parte dos alunos. A experiência vivenciada pelos alunos do $6^{\circ}$ ano, influenciará seus familiares sobre a importância de se alimentar bem, reduzindo custos, diminuindo o desperdício e aumentando o valor nutricional das suas refeições.

Palavras-chave: Aproveitamento integral dos alimentos; ambiente escolar; lixo orgânico.

\begin{abstract}
The research highlights the importance of full utilization of food for good health, minimizing waste and the reduction of the production of organic waste. With the objective, raise awareness among students of a public school in the city of Três Pontas MG about the full utilization of food. The work was through a questionnaire which gave support for a lecture that occurred, in which was discussed the benefits of full use of food. Then a recipe was prepared with the participation of students and then built a book of recipes that use food entirely. At the end of the project is perceived that the idea sensitized most of them. Fully enjoy the food not does well only to the environment and society, but also to body and mind. The situation experienced by the students of the 5th grade, will influence their families about the importance of eating well, reducing costs, reducing waste and increasing the nutritional value of your meals.
\end{abstract}

Keywords: Fully usage of food; school environment; organic garbage. 


\section{INTRODUÇÃO}

A alimentação é a base da vida, nos fornece energia, nutrientes, permitindo um equilíbrio do organismo. A utilização integral dos alimentos é uma maneira de promover a qualidade na alimentação e tem também como consequência a diminuição do lixo. Ou seja, aproveitar integralmente os alimentos não faz bem só ao meio ambiente e a sociedade, mas também ao corpo e à mente.

Segundo Badawi (2011), utilizar o alimento em sua totalidade significa mais do que economia. Significa usar os recursos disponíveis sem desperdício, reciclar, respeitar a natureza e alimentar-se bem, com prazer e dignidade.

Assim, o espaço escolar se torna um local privilegiado para se por em prática e disseminar a ideia que a alimentação saudável e a utilização integral dos alimentos é ponto fundamental para a vida.

De acordo com Valente (2002), uma prática de educação alimentar é adequada quando contribui para a construção de seres humanos saudáveis, conscientes de seus direitos e deveres e de sua responsabilidade para com o meio ambiente e com a qualidade de vida de seus descendentes.

O aproveitamento integral dos alimentos é a utilização de um determinado alimento na sua totalidade. A falta de informação sobre os princípios nutritivos e o aproveitamento dos alimentos gera o desperdício de toneladas de recursos alimentares. Por meio do aproveitamento integral dos alimentos é possível combater essa situação, pois o mesmo utiliza casca, talo, polpa e semente; com isso diminui os gastos com alimentação, reduz-se o desperdício de alimentos melhorando-se a qualidade nutricional da preparação, pois para muitos alimentos o teor de nutrientes na casca e no talo é maior em relação à polpa de alguns alimentos (GONDIM et al., 2005).

É preciso que, além da família, a escola contribua para que as crianças se conscientizem sobre o que é uma alimentação saudável, através da orientação e exemplos de condutas alimentares, já que as crianças têm como modelo de comportamento alimentar os adultos, principalmente pais e professores.

Incentivar o aproveitamento integral dos alimentos é uma medida eficaz no sentido de educar a população e nada melhor que começar pela escola, local onde além de realizarem uma refeição também pode-se formar opiniões que serão disseminadas. 
Pesquisa sobre o consumo consciente dos brasileiros realizada pelo Instituto Akatu envolvendo mais de 1200 pessoas revela que mais da metade dos participantes não fazem o uso do aproveitamento dos alimentos (MATTAR, 2007).

A alimentação da maioria dos alunos da escola é de boa qualidade, porém pode ser enriquecida com partes dos alimentos, cascas, folhas e caules, que muitas vezes são descartadas.

Com isso o presente trabalho tem como objetivo sensibilizar a comunidade escolar de uma escola pública estadual do município de Três Pontas-MG, a utilizar os alimentos na sua totalidade evitando o desperdício, melhorando a economia e aumentando o valor nutricional dos preparos. Através de orientações e receitas preparadas com os alunos.

\section{Desperdício dos alimentos no Brasil}

Dados da Embrapa, mostram que o desperdício de alimentos no Brasil é alto, chegando a 26 milhões de toneladas ao ano, o que poderia alimentar 35 milhões de pessoas (EMBRAPA, 2007). De cada 100 caixas de produtos agrícolas colhidos, apenas 61 chegam à mesa do consumidor (Banco de Alimentos, 2008) e 60\% do lixo urbano produzido é de origem alimentar (EMBRAPA, 2007).

As frutas que mais sofrem perdas são o abacate (31\%), abacaxi (24\%), laranja (22\%), banana (40\%), mamão (30\%), manga (27\%) e morango (39\%) (EMBRAPA, 2007). Uma maneira de evitar o desperdício seria a utilização de todas as partes dos alimentos, o que ainda é bastante discutido, já que há poucos estudos abordando o tema, principalmente em relação ao valor nutricional, preparações e receitas que utilizem folhas, talos e sementes de frutas e hortaliças. Dessa forma, as informações do valor nutricional dos alimentos originados da agricultura são escassas e sua utilização pequena, gerando baixo aproveitamento do alimento e desperdício de partes consumíveis (GONDIM et al, 2005).

As partes não aproveitáveis dos alimentos poderiam ser utilizadas enfatizando o enriquecimento alimentar, diminuindo o desperdício e aumentando o valor nutricional das refeições, pois talos e folhas podem ser mais nutritivos do que a parte nobre do vegetal como é o caso das folhas verdes da couve-flor que, mesmo sendo mais duras, contêm mais ferro que a couve manteiga e são mais nutritivas que a própria couve-flor (SOUZA et al., 2007). 
De acordo com Rocha et al. (2008), cascas, talos e folhas são boas fontes de fibras e lipídios, tendo-se como exemplos as sementes de abóbora; talos de brócolis, de couve, de espinafre; cascas de banana, de laranja, de limão, de rabanete e folhas de brócolis.

As cascas e sementes das frutas desperdiçadas pela maioria da população apresentam segundo análises físico-químicas, de modo geral uma quantidade de nutrientes maiores em relação às próprias partes comestíveis das frutas. As cascas das frutas podem contribuir com a diminuição do desperdício de alimentos por ser fonte alternativa de nutrientes (GONDIM et. al, 2005).

As cascas das hortaliças são fontes de fibras, vitaminas e sais minerais, que atuam nos organismos humanos como antioxidante (fatores que evitam o envelhecimento da pele); além disso, regularizam o intestino, previnem a anemia e auxiliam no processo de cicatrização (CASTELL,2004).

Neste âmbito conhecer o conceito de Segurança Alimentar e Nutricional (SAN) é iniciar a compreensão de um problema de saúde pública que atinge a todas as classes sociais: o desperdício dos alimentos. SAN é a realização do direito de todos ao acesso regular e permanente a alimentos de qualidade e em quantidade suficiente, com base em práticas alimentares saudáveis (CONSEA, 2004).

Estudos mostram que o desperdício alimentar está relacionado a vários fatores que vão desde a colheita, manipulação, forma de preparo inadequado, armazenamento, transporte inadequado, hábitos culturais e até mesmo a estrutura e característica diferenciadas de cada alimento (SANTOS, 2008).

\section{Aproveitamento integral dos alimentos no ambiente escolar}

Uma das funções da alimentação é garantir as necessidades do corpo. Uma boa alimentação é aquela rica em nutrientes que dão energia, promovem o crescimento e mantêm o corpo saudável. Com o passar do tempo os hábitos alimentares foram se modificando, e um dos motivos dessa mudança foi a "correria" da sociedade moderna. Para tornar a vida mais prática as pessoas consomem cada vez mais produtos industrializados, que por sua vez possuem vários aditivos que podem causar um impacto na saúde. Além disso, as pessoas nem se preocupam em ler o rótulo para se informar do que está sendo consumido. $\mathrm{O}$ uso do rótulo e das informações nutricionais pode 
transformar esse instrumento em ferramenta efetiva para escolhas de alimentos mais saudáveis pela população (BRASIL, 1998).

Uma das classes mais atraídas com esses alimentos são as crianças, que consomem cada vez mais bolachas, salgadinhos e doces que associada ao fator da vida sedentária pode ocasionar a obesidade e doenças como as citadas acima. Para que uma criança possua bons hábitos alimentares é necessário iniciar a educação alimentar desde cedo. A Família e a Escola são grandes colaboradoras para criar nas crianças hábitos de uma alimentação mais adequada às reais necessidades do organismo. Considera-se a Escola neste processo, pois ela é o local onde a criança passa grande parte do seu tempo. Para Schmitz et al (2008, p. 313), a cantina deve ser um espaço que reforce e estimule a prática de hábitos alimentares saudáveis. $\mathrm{O}$ ato de comer está relacionado a valores sociais, culturais e sensoriais. Na maioria das vezes, comer é um momento de prazer e confraternização com os amigos e familiares. Uma boa alimentação não precisa ser cara, pois pode ser feita com alimentos naturais, produzidos na região em que se vive (BRASIL, 1998).

A alimentação escolar é garantida, por meio da transferência de recursos financeiros advindos do Programa Nacional de Alimentação Escolar (PNAE), que foi implantado em 1955, para atender toda a Educação Básica, de matriculados em escolas públicas e filantrópicas. Atualmente, o valor repassado pela União, por dia letivo, é de $\mathrm{R} \$ 0,22$ por aluno. Os recursos destinam-se a compra de alimentos pelas Secretarias de Educação dos Estados e do Distrito Federal e pelos municípios (BRASIL, 2009).

Seu objetivo é atender as necessidades nutricionais dos alunos durante sua permanência em sala de aula, contribuindo para o crescimento, o desenvolvimento, a aprendizagem e o rendimento escolar dos estudantes, bem como promover a formação de hábitos alimentares saudáveis (BRASIL, 2009).

Segundo Gondim et al (2005), com o aproveitamento integral dos alimentos é possível reduzir o custo das preparações, contribuir para diminuição do desperdício alimentar, aumentar o valor nutricional e tornar possível a elaboração de novas preparações.

Oferecer uma alimentação balanceada desde a infância favorece níveis ideais de saúde, crescimento e desenvolvimento intelectual, influenciando diretamente no nível de aprendizagem, reduzindo transtornos educacionais causados por deficiências nutricionais, além de prevenir futuras doenças (LOPEZ; BRASIL, 2004). 


\section{Educação Ambiental na prática de aproveitamento dos alimentos}

Com relação aos hábitos alimentares e relacionando à escola, Fisberg e colaboradores (2010, p. 1) disseram que,

À medida em que a criança passa a frequentar a escola e a conviver com outras crianças, ela conhecerá outros alimentos, preparações e hábitos. Os adultos são modelos, delineando as preferências alimentares das crianças. Os vínculos afetivos poderão influenciar positiva ou negativamente na fixação dos padrões de consumo alimentar. É grande a influência da televisão na formação dos hábitos alimentares.

Desta forma, a Educação Ambiental na escola é o meio indispensável para criar e aplicar formas cada vez mais sustentáveis de interação entre sociedade e natureza, como o aproveitamento dos alimentos.

Além disso, a Educação Ambiental pode oferecer informações conceituais e trabalhar a mudança de atitudes na formação de valores por meio de dinâmicas de ensino e aprendizagem de procedimentos, pondo em prática sua capacidade de atuação (SILVA; SOUSA, 2011).

O Tema Transversal Meio Ambiente dos PCNs (1997, p.187) destaca também:

Proporcionar um ambiente escolar saudável e coerente com aquilo que ela pretende que seus alunos apreendam, para que possa, de fato, contribuir para a formação da identidade como cidadãos conscientes de suas responsabilidades com o meio ambiente e capazes de atitudes de proteção e melhoria em relação a ele.

Para tanto, a Educação Ambiental vem auxilia professores e pais na orientação de crianças e adolescentes na busca de prática de informações relacionadas ao Meio Ambiente e a inter-relação com outros fatores como Educação alimentar e Nutricional, Agrotóxico e Saúde para o bem estar de todos.

Neste sentido, torna-se imprescindível destacar também a importância da Lei $n^{\circ}$ 11.974 de 2009, que dispõem sobre a aquisição, elaboração e distribuição da merenda escolar e a responsabilidade do poder público representado pela instituição, para que crianças e adolescentes entendam e estabeleça inter-relações entre cenário econômico e social, Meio Ambiente, Desenvolvimento Sustentável. E destaca também que a instituição ofereça condições saudáveis e coerentes para a formação de cidadãos conscientes de sua responsabilidade frente ao Meio Ambiente e a Sustentabilidade para as gerações presente e futura. Responsabilidade essa que segundo o Ministério da Saúde (2005), é de todos, poder público, iniciativa privada e sociedade (SILVA; SOUSA, 2011). 


\section{METODOLOGIA}

O presente estudo é uma pesquisa qualitativa que visa promover a qualidade nutricional da merenda escolar fazendo o uso integral dos alimentos. Segundo Neves (1996), a pesquisa qualitativa costuma ser direcionada, ao longo do seu desenvolvimento; além disso, não busca, enumerar ou medir eventos, e geralmente não emprega instrumental estatístico para análise de dados; seu foco de interesse é amplo e parte de uma perspectiva diferenciada da adotada pelos métodos quantitativos. Dela faz parte a obtenção de dados descritivos mediante contato direto e interativo do pesquisador com a situação objeto de estudo.

A presente pesquisa aconteceu em uma escola estadual na cidade de Três Pontas, com alunos do $6^{\circ}$ ano do ensino fundamental II.

A pesquisa aconteceu nos meses de agosto, setembro e outubro do ano de 2014 no horário da disciplina de Ciências, e foram utilizadas 4 aulas, sendo uma por semana. Em cada aula aconteceu uma atividade.

$\mathrm{Na}$ aula I, foi feito um levantamento, através de um questionário semiestruturado, sobre que conhecimento os alunos têm a respeito da utilização da alimentação alternativa.

O questionário, segundo Gil (1999, p.128), pode ser definido:

Como a técnica de investigação composta por um número mais ou menos elevado de questões apresentadas por escrito às pessoas, tendo por objetivo o conhecimento de opiniões, crenças, sentimentos, interesses, expectativas, situações vivenciadas etc.

Em seguida na aula II, os alunos foram informados sobre importância da alimentação alternativa, através de aula dialógica com a pesquisadora, onde foi falado sobre a importância dos alimentos alternativos. A pesquisadora trabalhou com os dados analisados do questionário, para que tenha uma noção sobre o que abordou na aula.

$\mathrm{Na}$ aula III os alunos trouxeram escrito uma receita que tenha como princípio a alimentação alternativa, em seguida foi selecionado por eles uma receita para ser realizada na escola. Os ingredientes foram separados e trazidos de casa para a preparação na escola, no qual os alunos fizeram juntos a receita com o auxilio da pesquisadora.

Por último, na aula IV, foi confeccionado um caderno de receitas com as receitas trazidas pelos alunos, assim toda comunidade escolar tenha acesso as informações 
nutricionais e benefícios do aproveitamento integral dos alimentos, e também a ausência de risco do seu uso e algumas receitas.

Com isso, a atividade integra a teoria a prática além de explorar o trabalho coletivo entre os alunos.

\section{RESULTADOS E DISCUSSÃO}

A pesquisa iniciou com a distribuição de questionários semiestruturados para alunos do $6^{\circ}$ ano com a intenção de conhecer o que os alunos sabem a respeito da utilização da alimentação alternativa. Os estudantes que participaram da pesquisa têm em média 12 anos (Fig.1).

Figura 1: Alunos respondendo o questionário.

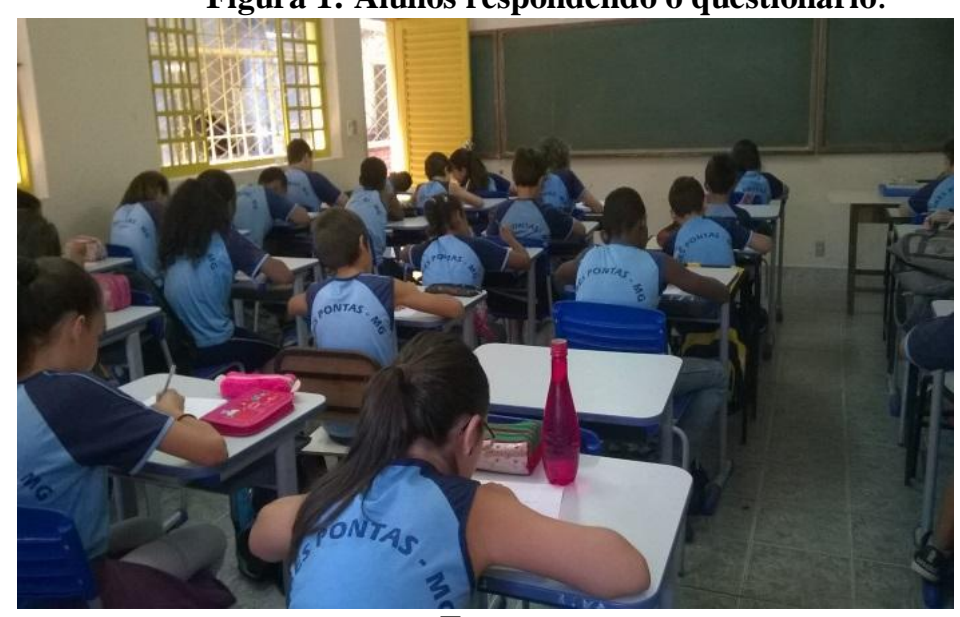

Fonte: autores

O questionário continha 6 questões e na primeira pergunta, questionou-se:” Aproveitamento integral dos alimentos é o mesmo que reaproveitamento de alimentos?" (Gráfico 1).

Gráfico 1: Aproveitamento Integral dos alimentos é o mesmo que reaproveitamento de alimentos?

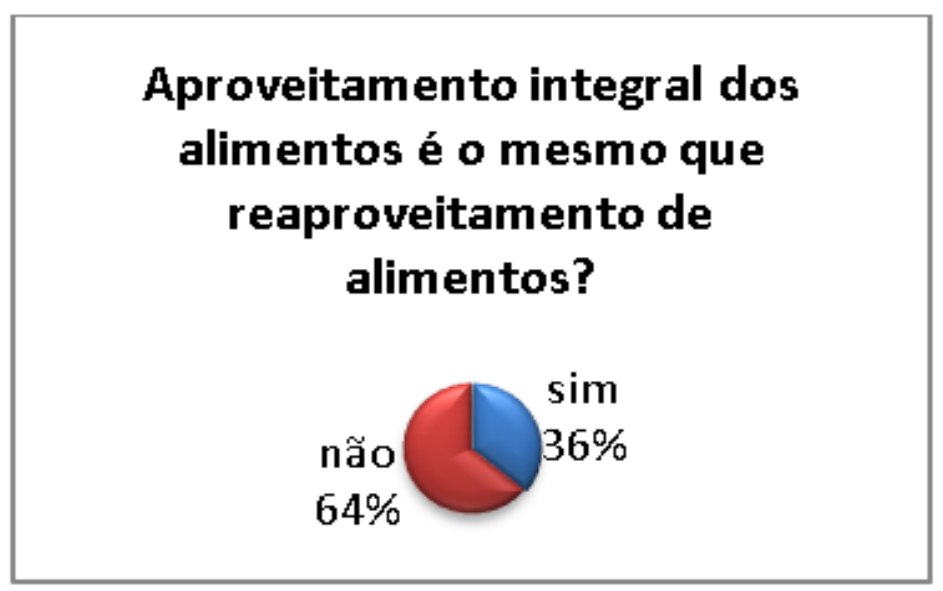

Fonte: autores 
Observamos que $64 \%$ dos alunos, responderam que não, isso mostra que ainda uma boa parte dos alunos não sabem diferenciar aproveitamento integral e reaproveitamento de alimentos. Faz-se necessário deixar claro a diferença entre Reutilização de Alimentos e Aproveitamento Integral dos Alimentos, onde o Reaproveitamento é quando o alimento já foi preparado e houve sobra nas panelas, sendo utilizado como ingrediente em outra preparação. $\mathrm{O}$ aproveitamento total dos alimentos é a utilização de um determinado alimento na sua totalidade. A falta de informações sobre os princípios nutritivos de cascas, talos, folhas, e sementes, leva a população a jogar estas partes no lixo, gerando o desperdício de toneladas de recursos alimentares (OLIVEIRA et al, 2002 apud PLACIDO; VIANA, 2012).

Na questão 2, indagou-se sobre os benefícios de se aproveitar integralmente os alimentos. E $48 \%$ dos alunos responderam que evita o desperdício, 47\% que assim consomem mais nutrientes e apenas $5 \%$ acredita que não há nenhum benefício.

Gráfico 2: Benefícios de se aproveitar integralmente os alimentos.

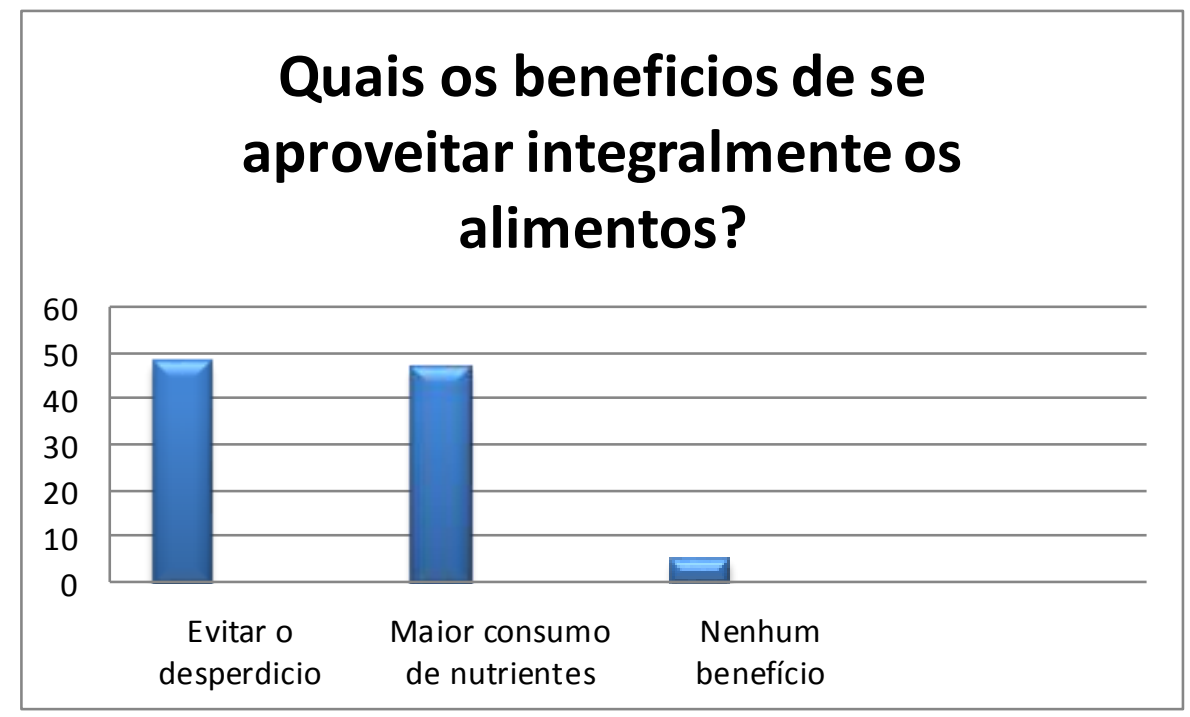

Fonte: autores

Já na questão 3, quando perguntado sobre poder usar talos, folhas e sementes na alimentação, todos responderam sim, o que demonstra um ganho, pois se a alimentação alternativa já está sendo inserida no cotidiano deles isso pode significar bons hábitos alimentares.

Na questão 4, indagou-se: "Você já se alimentou com uma refeição que tenha o aproveitamento integral do alimento?”. Das respostas obtivemos: 28\% dos alunos disseram que não e dos $72 \%$ que responderam sim, relataram que gostaram muito e não 
houve alteração no sabor e os pratos mais citados foram: batata frita com a casca, suco de couve com laranja, talos de couve e brócolis refogada.

Pesquisa utilizada pelo Instituto Akatu com mais de 1200 pessoas revela que $60 \%$ dos participantes já ouviram falar em aproveitamento integral dos alimentos, porém $8,3 \%$ disseram que aproveitam os talos, sementes, cascas e folhas dos alimentos (Mattar, 2007).

Na quinta questão perguntou-se se a utilização integral do alimento, só deve ser feita por pessoas de baixa renda e todos disseram não. Alguns complementaram sua resposta dizendo que deve ser feita por todas as pessoas.

$\mathrm{Na}$ última questão, questionou-se aonde vão os talos, cascas e folhas da casa de cada um deles. E $44 \%$ disseram que vão para o lixo, $28 \%$ que parte é utilizada e o restante vai para o lixo e os outros $28 \%$ afirmaram que se aproveitam totalmente os alimentos. Segundo Mattar (2007, f. 1):

No Brasil são produzidas 43,8 milhões de toneladas de detritos por ano. Cerca de $65 \%$ de total é representado por lixo orgânico, formado de restos de alimento; $25 \%$ é composto de papel; $4 \%$ de meta; $3 \%$ de vidro e $3 \%$ de plástico.

Com isso, se torna de suma importância desenvolver atividades que valorizem o aproveitamento integral dos alimentos, pois além de proporcionar benefícios a saúde, também diminuímos o lixo orgânico.

Os dados apresentados no questionário foram de grande valia para nortear a palestra para os alunos.

Uma das questões que norteou a palestra sobre Aproveitamento Integral dos Alimentos apresentada aos alunos foi sobre os benefícios para saúde e também para o ambiente. Também foi abordado na palestra o ganho nutricional com os alimentos alternativos. Segundo Evangelista (2001, p. 45):

Reduzir o desperdício de alimentos, formar hábitos alimentares saudáveis e adequados, amenizar os prejuízos e promover a melhoria da qualidade de vida das pessoas, se torna hoje peça fundamental. Com um reaproveitamento abrangente, o desperdício que ocorre na manipulação diária de produtos de hortifrútis seria aproveitado para fins nutricionais, amenizando assim possíveis carências da população.

Durante a palestra os alunos demonstraram grande interesse e a participação foi efetiva. Perguntaram se o aproveitamento integral não altera o sabor, se não faz mal, porém, o que mais foi relatado é sobre a prática já existente da utilização integral ou 
reaproveitamento do alimento nas suas casas: como sucos, xaropes, refogados e bolinhos.

Após a palestra solicitamos que os alunos trouxessem de casa alguma receita que realizasse o aproveitamento integral dos alimentos.

Em seguida foi feita a seleção da receita, que seria realizada na escola. A maioria dos alunos optaram pela receita do Bolo de Laranja inteira e alguns alunos se prontificaram em trazer algum ingrediente.

Os alunos foram levados para cozinha da escola e foram auxiliados pela pesquisadora (Fig. 2, 3 e 4) no corte das laranjas e manuseio do liquidificador.

Figura 2: Higienização das laranjas.

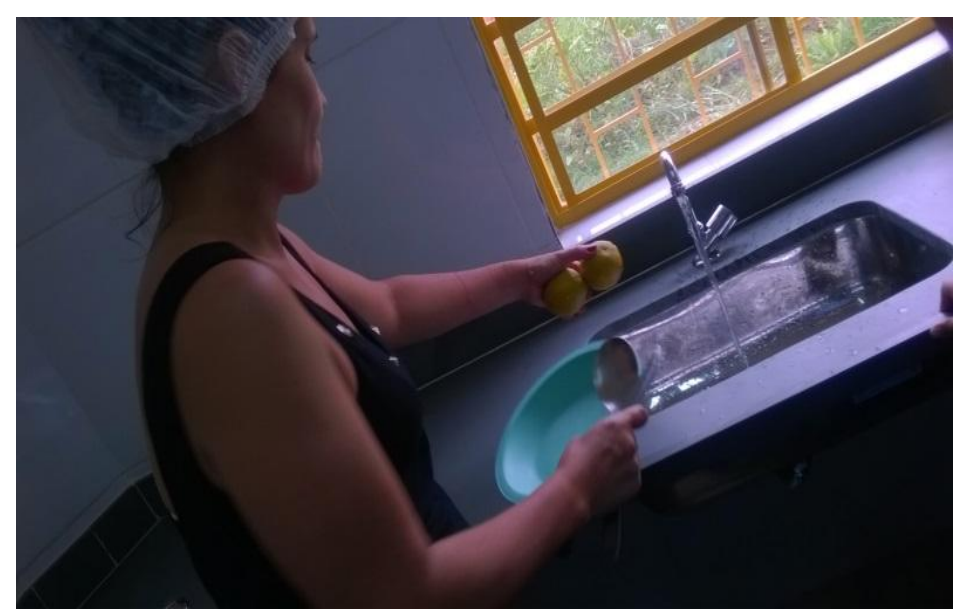

Fonte: autores

Figura 3: Corte das laranjas.

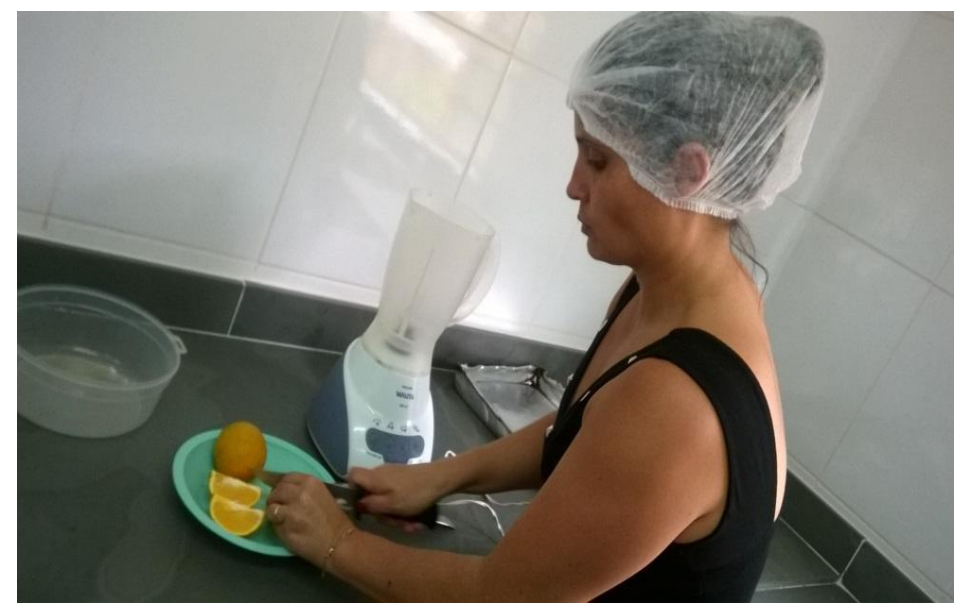

Fonte: autores

Figura 4: Preparo da receita. 


\section{Ensino, Saúde e Ambiente - V10 (1), pp. 203-217, Abril. 2017}

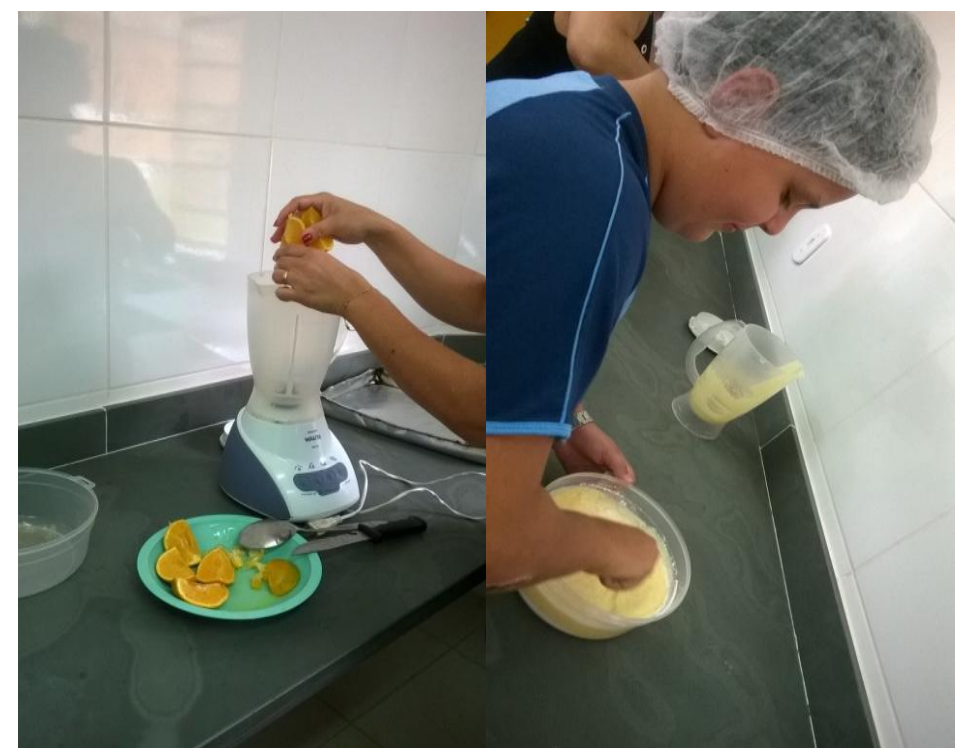

Fonte: autores

Todos os alunos participaram da atividade e depois do bolo pronto, todos provaram e aprovaram o bolo que, só dispensa as sementes (Fig. 5 e 6).

Figura 5: Bolo pronto

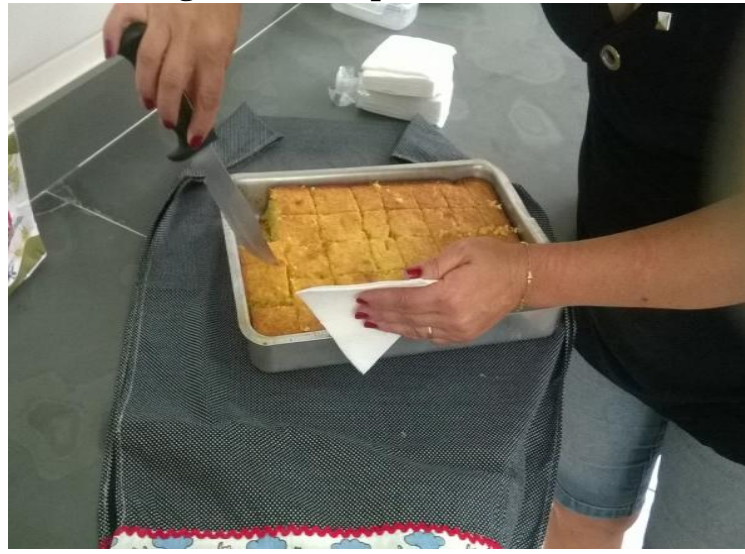

Fonte: autores
Figura 6: Alunos experimentando o bolo

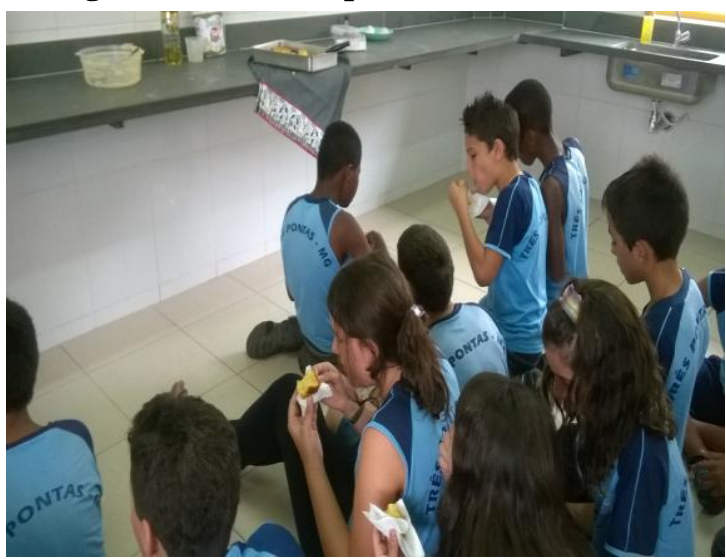

Fonte: autores

Com as receitas que foram trazidas pelos alunos, foi realizada uma seleção para verificar quais eram realmente de aproveitamento integral do alimento. E em seguida foi confeccionado um Caderno de receita. A escola disponibilizou as cópias que foram distribuídas para todos alunos, professores e funcionários. 


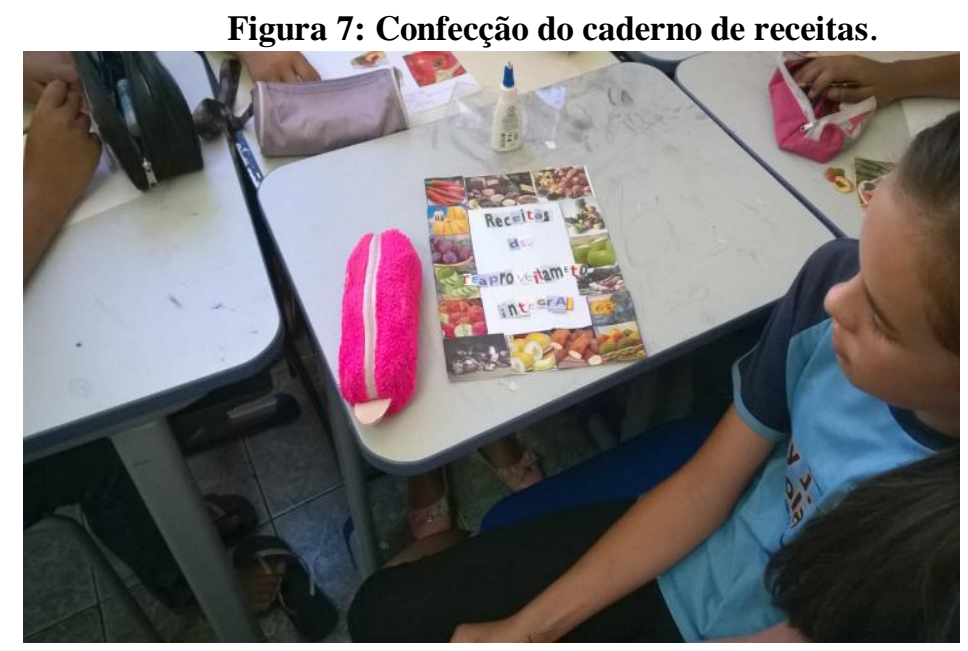

Fonte: autores

A educação ainda é a saída para diversos problemas. Ter este instrumento em mãos possibilita que esclarecimentos cheguem as comunidades com maior facilidade. É relevante conhecer as maneiras de se aproveitar integralmente os alimentos, não somente pelo enriquecimento nutricional mas, também pela necessidade da diminuição do lixo orgânico. É nas pequenas ações que se desperta atitudes duradouras.

\section{CONSIDERAÇÕES FINAIS}

Considerando o objetivo da pesquisa que é demonstrar a experiência de promoção da ideia do aproveitamento integral dos alimentos conclui-se que o projeto foi capaz de provocar e estimular os alunos para o tema de aproveitamento total dos alimentos.

Toda vivência despertou para questões de diminuição dos gastos com alimentos, desperdícios, gestão do lixo e aumento nutricional dos alimentos preparados, já que as partes descartadas contêm nutrientes.

Os alunos interagiram e demonstraram assimilação do sentido do tema proposto, discutindo na aula dialógica as suas experiências e participando ativamente do preparo do bolo de laranja e da construção do caderno de receita.

\section{REFERÊNCIAS BIBLIOGRÁFICAS}

ALBUQUERQUE, D. L. B.; MENEZES, C. S. Educação alimentar na escola: em busca de uma vida saudável, 2010. 25f. Universidade Federal de Pernambuco.PE 2010. 
Disponível em: <www.ufpe.br/ce/imagens/Graduação-pedagogia>. Acesso em: 19 de abril de 2014.

BADAWI, C. Aproveitamento Integral dos Alimentos: Melhor Sobrar do que faltar? São Paulo, 2014. Disponível em: <http://www.nutriciencia.com.br>. Acesso em: 17 de abril de 2014.

BRASIL. Portaria n²7, de 13 de janeiro de 1998. Aprova o Regulamento Técnico referente à Informação Nutricional Complementar (declarações relacionadas ao conteúdo de nutrientes), constantes do anexo desta portaria. Diário Oficial da União; Poder Executivo, de 16 de janeiro de 1998.

CASTELL, G. S. Larousse da Dieta e da Nutrição. São Paulo: Larousse do Brasil. p. 9-33. 2004.

CONFERENCIA NACIONAL DE SEGURANÇA ALIMENTAR E NUTRICIONAL, 2., 2004, Salvador. Anais... Salvador, 2004

EMBRAPA. O papel dos bancos de alimentos na redução do desperdício de alimentos. Set, 2007. Disponível em: <http://pessoal.utfpr.edu.br/marlenesoares /arquivos/BancodeAlimentosEmbrapa.pdfroberto_machado_-_19.09.pdf/view>. Acesso em: 10 maio 2014.

EVANGELISTA, J. Tecnologia de alimentos. 2. ed. Rio de Janeiro/São Paulo: Atheneu, 2001.

GONDIM, J. A. M.; MOURA, M. F. V.; DANTAS, A. S.; MEDEIROS, R. L. S.; SANTOS, K. M. Composição Centesimal e de Minerais em Casca de Frutas. Revista de Ciências e Tecnologia de Alimentos. São Paulo, v.25, n.4, p.825-827, out./dez.2005.

LOPEZ, F.A.; BRASIL, A.L.D. Nutrição e Dietética em Clínica Pediátrica. São Paulo: Atheneu, 2004.

MALUF, R. S.; MENEZES, F.; VALENTE, F. L. Contribuição ao Tema da Segurança Alimentar no Brasil. Revista Cadernos de Debate, Campinas, v.4, p.66-88, 1996.

MATTAR, H. Caderno Temático: a nutrição e o consumo consciente. São Paulo, 2007. Disponível em <http://www.akatu.org.br>. Acesso em: 13 de outubro de 2014.

NICÁCIO, V. N.; VIANA, A. C. Aproveitamento integral do alimento como forma de educação nutricional, diminuição do desperdício e desenvolvimento social, 2012,. 7. In: CONNEPI, 7., 2012, Palmas, TO. Anais.... Palmas, TO, 2012.

NUNES, J. T. Aproveitamento integral dos alimentos: Qualidade nutricional e aceitabilidade das preparações, 2009, 65F (Monografia para obtenção do grau de Especialista em Qualidade de Alimentos, Univ. De Brasília, UnB, Br), Brasília 2009. Disponível em: <bdm.bce.unb.br/bitstream/10483/1037/1/2009-

JulianaTavaresNunes.pdf.> Acesso em 21 de abril de 2014. 
PONTIFÍCIA UNIVERSIDADE CATÓLICA DE MINAS GERAIS. Pró-Reitoria de Graduação. Sistema de Bibliotecas. Padrão PUC Minas de Normalização: normas da ABNT para apresentação de projeto de pesquisa. Belo Horizonte, 2010. Disponível em <http://www.pucminas.br-bibloteca> Acesso em: 19 de abril de 2014.

ROCHA, S. A. LIMA, G.; LOPES, A. M.; BORGUINI, M. G. CICCONE, V. R.; BELUTA, I. Fibras e Lipídios em Alimentos Vegetais Oriundos do Cultivo Orgânico e Convencional. Revista Simbio de Nutrição, Campinas, v.14, p.35-40, 2001.

SANTOS, M. H. O. Desperdício de Alimento e sua interferência no meio ambiente. Goiânia: Instituto Construir e conhecer, 2008. v.5.

SOUZA, J. C.; MAURO, A. K.; CARVALHO, H. A.; MONTEIRO, M. R. P. MARTINO, H. S. D. Qualidade Proteica de Multimisturas Distribuídas em Alfenas, Minas Gerais, Brasil. Revista Nutrição, nov./dez.2006.

VALENTE, F. L. S. Direito humano à alimentação: desafios e conquistas. São Paulo: Cortez Editora, $1^{\text {a }}$ ed., 2002. 